\title{
Compare the clinical management of warfarin among physician versus pharmacist-led coagulation clinic: structured systematic review.
}

\author{
Syed Wasif Gillani ${ }^{1}$, Lojain I. Alsubaihi ${ }^{1}$, Hisham A. Zaghloul ${ }^{1}$, Irfan Altaf Ansari ${ }^{2}$, Mohi Iqbal MA ${ }^{3}$, \\ Mirza R. Baig 4 \\ ${ }^{1}$ Department of Clinical Pharmacy, College of Pharmacy, Taibah University, Al Madinah Al Munawarrah, Saudi Arabia \\ ${ }^{2}$ Department of Histopathology, College of Medicines, Taibah University, Al Madinah Al-Munawarrah, Saudi Arabia \\ ${ }^{3}$ Department of Pharmacology, College of Pharmacy, Taibah University, Al Madinah Al-Munawarrah, Saudi Arabia \\ ${ }^{4}$ Department of Clinical Pharmacy, Dubai Pharmacy College, United Arab Emirates (UAE)
}

\begin{abstract}
The aim of the study was to assess the management of INR therapeutic range as an estimate for achieving therapeutic outcome and estimate sub/supra-therapeutic INR's among physician versus pharmacist-led clinics. Articles were searched in: PubMed, Cochrane, Springer, Science Direct, and Wiley. The search was limited to the English language from 2010 to 2016. The inclusion criteria of the articles keywords such as warfarin, management, pharmacist, physician, therapy, clinic, and anticoagulation were used and GRACE guideline was used to assess the quality of these research articles. A total of $\mathbf{1 0 5 0}$ articles were found with the relative subject, after excluding the duplicates more than $50 \%$ have been excluded, following the title and reviewing the abstract another $133(12.67 \%)$ were ruled out, and 6 studies were included in the systematic review. In multiple studies pharmacist-Led coagulant clinic showed better outcomes with warfarin anticoagulant therapy. Patients exhibits high satisfaction levels and least warfarin induced complications in comparison with those results obtained with physician-led clinic. It is found that patients-oriented care has not been reported in the retrieved literature, which might open a room for researcher to determine the impact of services provided by pharmacists on individual patient-centered outcomes.
\end{abstract}

Keywords: Pharmacist, Clinical pharmacy, Warfarin, Healthcare services.

Accepted on January 17, 2018

\section{Introduction}

Warfarin was first introduced to the healthcare system in 1950 as Coumadin sodium [1] for the management of Atrial Fibrillation (A-Fib), mechanical prosthetic heart valves, Deep Vein Thrombosis (DVT), coronary artery disease and stroke [1,2]. Warfarin exhibits serious adverse effects due to its Narrow Therapeutic Index (NTI) [1] which might be life threatening due to the high individual variability in doserelated response [3]. Patients' risk to substantial bleeding due to over warfarinization as well as persistent clotting events as in case of stroke or pulmonary embolism with sub therapeutic warfarinization [4]. Altered warfarin pharmacokinetics and International Normalized Ration (INR) are factorized [5] by widely variable parameters such as eating habits, concurrent medications [5], disease status and herbal products [1]. Thus pharmacists play a vital role in the management, education, and counselling the patient to prevent the warfarin related emergency room visits [6]. Evidence also indicated that a pharmacist managed anticoagulation clinics will jeopardize to least to no side effects [7]. At present several hospitals have either contributed a pharmacist into their family clinic or have a pharmacist-led clinic, focusing toward more patient-centered care [8].

The aim of the present study was to assess the management of INR therapeutic range and estimate sub/supra-therapeutic INR's among physician versus pharmacist-led clinics and evaluation of the patient-oriented services to identify which one of them is more appropriate to be more patient-oriented that matter.

\section{Materials and Method}

Systemic review registration

CRD42017055422 (PROSPERO).

\section{Eligibility criteria}

Anticoagulant: Warfarin is the drug of choice as a stand-alone anticoagulant therapy for patients. 
Pharmacist-led clinic vs. physician: studies focus on either pharmacist managed clinic and/or physician managed clinic to see how both groups are achieving respective clinical outcomes.

INR measurements: INR is the Prothrombin Time (PT) of the patient over the normal PT value. The method of receiving and collecting the data should be specified and written clearly. While the INR value should be categorized into therapeutic INR (the normal INR for the patient's condition), subtherapeutic INR (below the patient's normal value), supratherapeutic INR (a higher value than the patient's normal value).

\section{Literature search}

Articles were searched in: PubMed, Cochrane, Springer, Science Direct, and Wiley. The search was limited to the English language from 2010 to 2016. Due to the inclusion criteria of the articles keywords such as warfarin, management, pharmacist, physician, therapy, clinic, and anticoagulation were used. For example, the PubMed research method was written as follows: (warfarin management), (anticoagulant management), (pharmacist and physician management).

\section{Study selection and data extraction}

Abstracts were screened to exclude studies that don't involve the following research criteria. Eligible studies were further reviewed for its quality (study design, length of study, intervention done, how they assessed the results and follow-up procedure). Patient characterization was also evaluated regarding age and indication of anticoagulation.

\section{Quality assessment}

Good Research for Comparative Effectiveness (GRACE) checklist is an 11-item checklist that was developed and used to review observational studies for quality and use-fullness in decision making [9]. The eleven items are categorized into two groups, the data and recording of the measurements, and the method, that was concerned in the study population and comparison between the groups [9].

\section{Results and Findings}

\section{Literature search}

A total of 1050 articles were found to be relative to the subject, after excluding the duplicates $>50 \%$ have been excluded. Following the title and reviewing the abstract another 133 $(12.67 \%)$ were ruled out, and 6 studies were included in the systematic review. The study flowchart is presented in Figure 1 and inclusion characteristics of articles are shown in Table 1.

\section{Quality assessment}

Not all the studies have included naïve participants [4,10-13] except only one [3]. Necessary information were recorded and stated objectively (therapeutic INR, supra-therapeutic INR, and sub-therapeutic INR), and few among them have shown missing data required to standardize measurements [3,11]. All the studies included have parallel groups and standard measured time and variables (Table 2).

Table 1. Summary of the articles included in the research.

\begin{tabular}{|c|c|c|c|c|c|c|}
\hline \multirow[t]{2}{*}{ Author } & \multicolumn{2}{|l|}{ Patients demographics } & \multirow{2}{*}{$\begin{array}{l}\text { Pharmacist } \\
\text { care } \\
\text { INR therapeutic } \\
\text { range }\end{array}$} & \multirow{2}{*}{$\begin{array}{l}\text { Physicians } \\
\text { care } \\
\begin{array}{l}\text { INR therapeutic } \\
\text { range }\end{array}\end{array}$} & \multirow[t]{2}{*}{$P$ value } & \multirow[t]{2}{*}{ Conclusion } \\
\hline & Inclusion criteria & $\begin{array}{l}\text { Exclusion } \\
\text { criteria }\end{array}$ & & & & \\
\hline \multirow[t]{3}{*}{ Garton [3] } & 18 y and older. & $\begin{array}{l}\text { Not seen } \\
\text { regularly in the } \\
\text { clinic. }\end{array}$ & $81.10 \%$ & $71.10 \%$ & \multirow[t]{3}{*}{$<0.0001$} & \multirow[t]{3}{*}{$\begin{array}{l}\text { Pharmacists can maintain the INR } \\
\text { ranges with patients via counselling } \\
\text { technique. }\end{array}$} \\
\hline & Male and female. & $\begin{array}{l}\text { Noncompliant } \\
\text { patients. } \\
\text { Pregnant or post- } \\
\text { partum. }\end{array}$ & & & & \\
\hline & $\begin{array}{l}\text { Valid anticoagulant } \\
\text { diagnosis. }\end{array}$ & & & & & \\
\hline \multirow[t]{2}{*}{ Motycka [4] } & $\begin{array}{l}\text { Warfarin therapy of a } \\
\text { minimum of } 14 \mathrm{~d} \text {. }\end{array}$ & $\begin{array}{l}\text { Warfarin therapy } \\
\text { less than } 14 \mathrm{~d} \text {. }\end{array}$ & $58.70 \%$ & $47.10 \%$ & \multirow[t]{2}{*}{$<0.0001$} & \multirow{2}{*}{$\begin{array}{l}\text { Clinical pharmacist at a nursing home } \\
\text { facility to maintain INR levels within } \\
\text { therapeutic range, and decreasing the } \\
\text { overall cost of managing those patients. }\end{array}$} \\
\hline & $\begin{array}{l}\text { Had at least one INR } \\
\text { measurement. }\end{array}$ & $\begin{array}{l}\text { Who needed } \\
\text { permanent } \\
\text { discontinuation } \\
\text { of warfarin. }\end{array}$ & & & & \\
\hline Elewa [10] & $\begin{array}{l}\text { Anticoagulation therapy } \\
\text { managed by the clinic. }\end{array}$ & $\begin{array}{l}\text { Enrolled in } \\
\text { another clinical } \\
\text { trial. }\end{array}$ & $76.8+-22.9 \%$ & Not valid & Not valid & $\begin{array}{l}\text { Quality of life, percentage of INR } \\
\text { therapeutic range and patient's } \\
\text { satisfactory complement the pharmacist } \\
\text { management. }\end{array}$ \\
\hline
\end{tabular}



systematic review

\begin{tabular}{|c|c|c|c|c|c|c|}
\hline \multirow{3}{*}{ Elewa [11] } & \multicolumn{6}{|l|}{$\begin{array}{l}\text { Followed by the clinic for at } \\
\text { least } 4 \mathrm{w} \text {. }\end{array}$} \\
\hline & $\begin{array}{l}\text { Joined the anticoagulation } \\
\text { clinic prior to April } 2014 \text {. }\end{array}$ & $\begin{array}{l}\text { Enrolled in } \\
\text { another clinical } \\
\text { trial. }\end{array}$ & $81.80 \%$ & $69.80 \%$ & $<0.001$ & $\begin{array}{l}\text { Pharmacist management achieved } \\
\text { better results in INR therapeutic ranges } \\
\text { than the doctors. }\end{array}$ \\
\hline & $\begin{array}{l}\text { Followed-up at a } \\
\text { pharmacist-based } \\
\text { anticoagulation clinic at } \\
\text { Alwakra or at the doctor- } \\
\text { based clinic at the Heart } \\
\text { Hospital. }\end{array}$ & $\begin{array}{l}\text { Started } \\
\text { anticoagulation } \\
\text { therapy less than } \\
6 \text { months ago. }\end{array}$ & & & & \\
\hline \multirow[t]{3}{*}{ Gupta [12] } & $18 \mathrm{y}$ and older. & Not written. & $\begin{array}{l}\text { Long-time users: } \\
58.1 \%\end{array}$ & $\begin{array}{l}\text { Long-time users: } \\
50.5 \%\end{array}$ & \multirow[t]{2}{*}{0.0008} & \multirow{3}{*}{$\begin{array}{l}\text { The pharmacist emphasizes patient } \\
\text { education on the use of warfarin, INR } \\
\text { results, monitoring, and tracking of } \\
\text { laboratory results. The pharmacist uses } \\
\text { evidence-based guidelines to determine } \\
\text { dosage adjustment algorithms, follow- } \\
\text { up, and appropriate patient } \\
\text { communication to discuss necessary } \\
\text { changes. }\end{array}$} \\
\hline & $\begin{array}{l}\text { An INR goal range of } 2.0 \text { to } \\
3.0 \text { were included. }\end{array}$ & & & & & \\
\hline & Consent was obtained. & & $\begin{array}{l}\text { All patients: } \\
57.5 \%\end{array}$ & All patients: $50 \%$ & 0.0004 & \\
\hline \multirow[t]{3}{*}{ Zhou [13] } & RCT studies. & $\begin{array}{l}\text { Studies whom } \\
\text { failed to meet the } \\
\text { eligibility criteria. }\end{array}$ & & - & $\begin{array}{lr}95 \% & \mathrm{Cl}=3.66 \\
(2.2-5.11) & \text { which } \\
\text { favors pharmacist. }\end{array}$ & \multirow{3}{*}{$\begin{array}{l}\text { The advantage of pharmacist in the } \\
\text { management of warfarin anticoagulation } \\
\text { therapy, safety and mortality are not } \\
\text { clear, but resulted in significantly better } \\
\text { patient satisfaction. Pharmacists can } \\
\text { perform an important role in warfarin } \\
\text { management. }\end{array}$} \\
\hline & $\begin{array}{l}\text { Used warfarin as an } \\
\text { anticoagulant. }\end{array}$ & & & & & \\
\hline & $\begin{array}{l}\text { Included pharmacists in } \\
\text { warfarin management. } \\
\text { Included a control group of } \\
\text { healthcare professionals. } \\
\text { Providing management. }\end{array}$ & & & & & \\
\hline
\end{tabular}

Table 2. Quality assessment of the articles using the GRACE checklist.

\begin{tabular}{|c|c|c|c|c|c|c|}
\hline \multicolumn{2}{|c|}{ GRACE checklist criteria } & \multirow{2}{*}{$\begin{array}{l}{[2]} \\
\text { Yes }\end{array}$} & \multirow{2}{*}{$\begin{array}{l}{[3]} \\
\text { Yes }\end{array}$} & \multirow{2}{*}{$\begin{array}{l}{[12]} \\
\text { Yes }\end{array}$} & \multirow{2}{*}{$\begin{array}{l}{[11]} \\
\text { Yes }\end{array}$} & \multirow{2}{*}{$\begin{array}{l}{[13]} \\
\text { Yes }\end{array}$} \\
\hline D1 & $\begin{array}{l}\text { Were treatment and/or important details of } \\
\text { treatment exposure adequately recorded for the } \\
\text { study purpose in the data source(s)? }\end{array}$ & & & & & \\
\hline D2 & $\begin{array}{l}\text { Were the primary outcomes adequately recorded } \\
\text { for the study purpose (e.g., available in sufficient } \\
\text { detail through data source(s))? }\end{array}$ & Yes & Yes & Yes & Yes & Yes \\
\hline D3 & $\begin{array}{l}\text { Was the primary clinical outcome }(\mathrm{s}) \text { measured } \\
\text { objectively rather than subject to clinical judgment } \\
\text { (e.g., opinion about whether the patient's condition } \\
\text { has improved)? }\end{array}$ & Yes & Yes & Yes & Yes & Yes \\
\hline D4 & $\begin{array}{l}\text { Were primary outcomes validated, adjudicated, or } \\
\text { otherwise known to be valid in a similar } \\
\text { population? }\end{array}$ & Yes & Yes & Yes & Yes & Yes \\
\hline D5 & $\begin{array}{l}\text { Was the primary outcome(s) measured or } \\
\text { identified in an equivalent manner between the } \\
\text { treatment/ intervention group and the comparison } \\
\text { group(s)? }\end{array}$ & Yes & Yes & Yes & Yes & Yes \\
\hline D6 & $\begin{array}{l}\text { Were important covariates that may be known } \\
\text { confounders or effect modifiers available and } \\
\text { recorded? }\end{array}$ & Yes & Yes & Yes & Yes & Yes \\
\hline M1 & $\begin{array}{l}\text { Was the study (or analysis) population restricted to } \\
\text { new initiators of treatment or those starting a new } \\
\text { course of treatment? }\end{array}$ & No & Yes & No & No & No \\
\hline M2 & $\begin{array}{l}\text { If one or more comparison groups were used, } \\
\text { were they concurrent comparators? If not, did the }\end{array}$ & Yes & Yes & Yes & Yes & Yes \\
\hline
\end{tabular}


authors justify the use of historical comparisons group(s)?

\begin{tabular}{lllll}
\hline M3 & $\begin{array}{l}\text { Were important covariates, confounding and effect } \\
\text { modifying variables taken into account in the } \\
\text { design and/or analysis? }\end{array}$ & Yes & Yes & Yes \\
\hline M4 & $\begin{array}{l}\text { Is the classification of exposed and unexposed Yes } \\
\text { person-time free of "immortal time bias"? }\end{array}$ & Yes & Yes & Yes \\
\hline M5 & $\begin{array}{l}\text { Were any meaningful analyses conducted to test Not applicable } \\
\text { key assumptions on which primary results are } \\
\text { based? }\end{array}$ & Not applicable & Not applicable & Not applicable \\
\end{tabular}

\section{Pharmacist led clinic}

Therapeutic INR: Patient following the pharmacist clinic had a "within range" INR yielding a percentage of $81.1 \%$ [3], $81.8 \%$ [11], 58.7\% [4], 76.8+-22.9\% [10], 57.5\% [12] and shown significant $[3,4,10,11,13]$ outcomes against the physicians managed group. In the meta-analysis, they exhibit odd ratio of 3.66 (95\% CI, 2.20-5.11, $\mathrm{P}<0.00001)$ [13].

Supra-therapeutic INR: Pharmacists-led clinics also achieved low prevalence of patients with supra-therapeutic INR $(5.2 \% 11)$ and $(16.9 \%)$ due to the low INR tests $(n=53)$ compared to the physicians group with $n=499$ INR tests4, with one major bleeding event $(0.67 \% /$ year $)$ [10]. Two articles showed non-significant results $(\mathrm{P}=0.0311)$ and $(\mathrm{P}=0.05394)$ with percentages of $2.4 \%$ [4] and $5.2 \%$ [11] respectively, and Zhou's pharmacist-managed group had a non-significant Odds Ratio (OR) of 0.89 (95\% CI, 0.56-1.44, P =0.64) [13]

Sub-therapeutic INR: Patients might spend less time being in the sub-therapeutic range with pharmacist-led clinic [4]. One of the studies showed that the pharmacist had only two thromboembolic events $(1.35 \% / y) \quad[10]$, and significant $(\mathrm{P}=0.007)$ findings were presented in Elwa's study with a percentage of $5.2 \%$, however Zhou showed a contrast nonsignificant findings of odd ratio (OR) 0.81 (95\% CI, 0.34-1.92, $\mathrm{P}=0.64)[13]$.

\section{Physician led clinic}

Therapeutic INR: A high percentage of $71.1 \%$ was obtained among patients with targeted INR as presented by Garton in 2011, in comparison with to $69.8 \%$ [11], $47.1 \%$ [4] and $50 \%$ [12] from other studies.

Supra-therapeutic INR: Motycka et al. study showed nonsignificant difference in the supra-therapeutic time between the two groups with $\mathrm{P}=0.03$ [11] and $3.6 \%$ [11], supporting the findings with Elwa's study; $\mathrm{P}=0.0539$ [4] and percentages of $2.4 \%[4]$.

However, in 2013 Gupta et al. had contrasting results, revealing that a physician-led clinic patients INR was scattered outside the therapeutic INR range more than those reported for the pharmacist-Led clinic.

Sub-therapeutic INR: Elwa et al. reported significantly high rates of sub-therapeutic INR range for those patients in physician-led clinic as compared to those results obtained pharmacists amounting to $44.06 \% 4$ and $7.1 \%$, respectively $(\mathrm{P}=0.007)$.

\section{Patient orientation}

A total of two studies had been reported about the Quality of Life (QOL), among the management rudiments. The metaanalysis showed an OR of $0.41(95 \% \mathrm{CI}, 0.01-0.81, \mathrm{P}=0.04)$ revealing a significant improvement in the pharmacistmanaged warfarin anticoagulation group [13]. Another study reported that the participants with anticoagulation treatment showed a significant high satisfaction level with anticoagulation treatment intervention (58 (44) vs. 82 (59)); $\mathrm{P}=0.009$ ) [10].

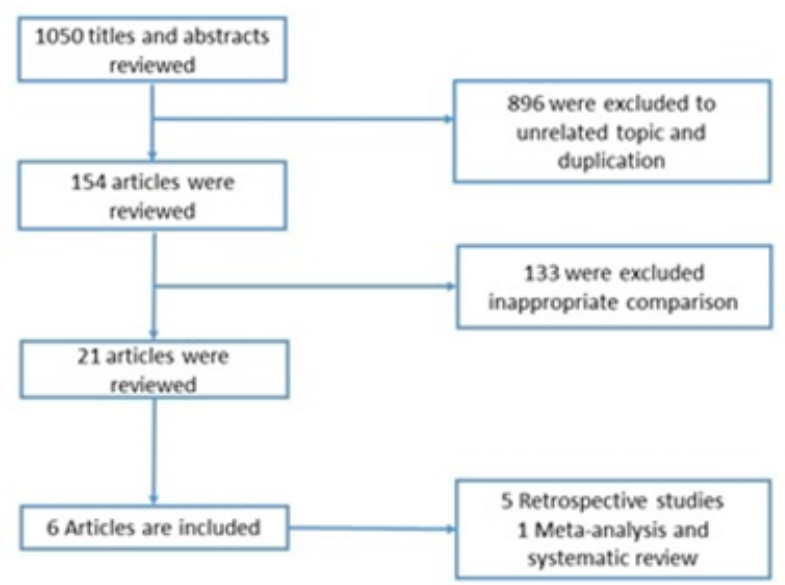

Figure 1. Study flow diagram.

\section{Discussion}

This systemic review aimed to evaluate the effectiveness of pharmacist-led clinic compared to a physician-led clinic in the last 10 years. The results showed that the pharmacist-led clinic achieved better clinical outcomes than physicians in anticoagulation control among patients using warfarin, manifested by most of the INR results that achieved within the targeted therapeutic range, thus prevails the primary objective of the study.

Similar findings were reported in several publications, Rudd et al. [14] reported that that the pharmacist-managed services had yielded a better anticoagulation control; contributing to 
reduction in the burden of hospitalization and emergency department visits [14]. Similarly another research confirmed the usefulness of the pharmacist intervention; as a result of reduction of the time required for anticoagulation monitoring and significant improvement in the QOL of the patients' [15].

However, a recent research article reported that there is no difference between the pharmacist managed practice and the physician's management towards safety and effectiveness when using the same guidelines with regard to in time within INR therapeutic range. The only difference found between both groups revealing that the pharmacist management used less INR testing which might improve cost-benefit over physicianled clinic [16].

The literature suggested high prevalence of achieved targeted therapeutic INR with increased satisfaction, and reduced both diagnostic cost and supra-therapeutic INR among patients with Pharmacist-Led clinic $[7,10,13,14]$. This could have attributed to pharmacist's knowledge on drug/herb interactions and drug dosing and monitoring $[1,16]$. All the research articles included in the present assessment concluded that the pharmacistmanaged clinic is certainly a better option than physician. There was no study among those six that focused on patientoriented care aspects. There were two studies discussed the patient satisfaction and confidence for better control on warfarin therapy $[10,13]$. Two studies also reported that the clinical pharmacists adjust the dose according to an established evidence based protocol, however the physician is usually influenced by his/her experience and clinical judgement. The physician changes the warfarin dose solely depending on the INR results with no further information on the patient health status. In contrast, the pharmacist-led services educate the patient on warfarin6, evaluate health status, life style changes, missed or added doses by mistake, diet management and concomitantly administered medications [1,5]. It is also reported that pharmacists are more capable to counselling techniques in community setting which will increase the therapeutic adherence and improve efficacy among patients with warfarin use [2,12].

Clinical pharmacists have an intensive training on anticoagulation management, focusing on handling the patients concerns and views on warfarin, making the patient more confident, satisfied and health-seeking behavior with pharmacists compared to physician [2].

\section{Conclusion}

Pharmacist-led clinic showed better outcomes with warfarin anticoagulant therapy in multiple studies. Patients exhibits high satisfaction levels and least complications compared with Physician-led clinic. It was found that patients-oriented care had not been reported in the literature, opening a room for researcher to determine the impact of pharmaceutical services on patients' outcomes.

\section{Limitations}

Obtaining the physicians data was a major hindrance to the authors and to the pharmacist himself. Not all studies had achieved the accuracy of collecting the data $[3,11]$. The small group size [4] might lead to a false statistical significance and the short term of follow-up [12]. Several studies had no data to compare their INR results at pre-post levels.

\section{References}

1. Dib J. Implementation of pharmacist-managed anticoagulation clinic in a saudi arabian health center. Hosp Pharm 2014; 49: 260-268.

2. Garton L, Joseph FC. A retrospective assessment comparing pharmacist-managed anticoagulation clinic with physician management using international normalized ratio stability. J Thrombos Thrombol 2011; 32: 426-430.

3. Motycka C. Potential benefits of warfarin monitoring by a clinical pharmacist in a long term care facility. J Thrombos Thrombol 2011; 33: 173-177.

4. Fleming H. Realizing pharmacists potential: pharmacist-led anticoagulation management services. Translator 2010; 4.

5. Young S. Comparison of pharmacist managed anticoagulation with usual medical care in a family medicine clinic. BMC Fam Pract 2011; 12.

6. Yamada K, Toshitaka N. Pharmacist-managed clinics for patient education and counseling in Japan: current status and future perspectives. J Pharm Health Care Sci 2015; 1.

7. Bishop L. Patients and physicians satisfaction with a pharmacist managed anticoagulation program in a family medicine clinic. BMC Res Notes 2015; 8.

8. Erickson AK. Anticoagulation revolution: optimizing care from all angles. Pharm Today 2013; 19.

9. GRACE Principles-Good research for comparative effectiveness. Graceprinciples.org. 2016.

10. Elewa HF. The first pharmacist-managed anticoagulation clinic under a collaborative practice agreement in Qatar: clinical and patient-oriented outcomes. J Clin Pharm Therap 2016; 41: 403-408.

11. Elewa H. Evaluation of pharmacist-based compared to doctor-based anticoagulation management in Qatar. J Eval Clin Pract 2016; 22: 433-438.

12. Gupta V, Stephen JK, Sarah T. Evaluation of differences in percentage of international normalized ratios in range between pharmacist-led and physician-led anticoagulation management services. J Pharm Pract 2015; 28: 249-255.

13. Zhou S. Comparing the effectiveness of pharmacistmanaged warfarin anticoagulation with other models: a systematic review and meta-analysis. J Clin Pharm Ther 2016; 41: 602-611.

14. Rudd KM, John GD. Comparison of two different models of anticoagulation management services with usual medical care. Pharmacotherapy 2010; 30: 330-338.

15. Verret L. Impact of a pharmacist-led warfarin selfmanagement program on quality of life and anticoagulation 
control: a randomized trial. Pharmacother J Human Pharmacol Drug Ther 2012; 32: 871-879.

16. Sargent R. Advantages of a warfarin protocol for long-term care pharmacists: a retrospective cohort study. Canadian Geriatr J 2016; 19.

\section{*Correspondence to}

Syed Wasif Gillani

Department of Clinical Pharmacy,

College of Pharmacy

Taibah University

Madinah Munawara

Kingdom of Saudi Arabia

Email: wasifgillani@gmail.com 